\title{
A NOVA TUTELA DE URGÊNCIA NAS AÇÕES CIVIS PÚBLICAS AMBIENTAIS: UM INSTRUMENTO DE EFETIVAÇÃO DA PROTEÇÃO AO MEIO AMBIENTE
}

\author{
Letícia Nalin Alves, Fábio Ferreira Morong
}

Universidade do Oeste Paulista-UNOESTE, Curso de Direito, Presidente Prudente, SP. E-mail: leticianalin@hotmail.com

\begin{abstract}
RESUMO
Este trabalho objetiva analisar a importância da concessão de tutelas de urgência nas ações civis públicas ambientais, uma vez que este é o principal instrumento processual utilizado no Brasil para proteger o meio ambiente. Busca-se ainda, verificar se as alterações nas concessões de tutelas provisórias, advindas com o Novo Código de Processo Civil, são aplicáveis às lides ambientais. O método aplicado foi o dedutivo legal, a partir da análise da legislação nacional e doutrinas. Concluiu-se que as regras introduzidas para a concessão de tutelas provisórias no Novo Código de Processo Civil são aplicáveis aos processos ambientais, e que eventuais concessões destas medidas de urgência nas ações civis públicas em matéria ambiental efetivam a proteção ao meio ambiente, uma vez que evitam ou minimizam os efeitos que o lapso temporal produziria na degradação do objeto tutelado nessas ações.

Palavras-chave: meio ambiente, tutela de urgência, microssistema processual ambiental, ação civil pública ambiental, Novo Código de Processo Civil.

\section{THE NEW TRUSTEESHIP OF URGENCY IN ENVIRONMENTAL CLASS ACTIONS: AN EFFECTIVE TOOL FOR PROTECTING THE ENVIRONMENT}

\begin{abstract}
This work aims to analyze the importance of emergency guardianships concession in environmental class actions, since this is the main procedural tool used in Brazil to protect the environment. The aim is to verify the changes in the provisional guardianships concessions stemming from the New Code of Civil Procedure shall apply to environmental litigations. The method applied was the legal deductive, from the analysis of national legislation and doctrines.It was concluded that the rules introduced for the granting of provisional guardianships in the New Code of Civil Procedure are applicable to environmental processes, and any concessions of these emergency measures in civil actions in environmental actualize the environmental protection, since avoid or minimize the effects that the time lapse produce the degradation of the object tutored in these actions.
\end{abstract}

Keywords: environment, emergency care, environmental procedural microsystem, environmental civil action, the New Civil Procedure Code.

\section{INTRODUÇÃO}

O meio ambiente equilibrado é um direito fundamental, previsto no artigo 225 do texto constitucional de 1988, que o ressalta como um bem de uso comum do povo e essencial à sadia qualidade de vida.

Ao longo da história da humanidade os direitos fundamentais sofreram transformações no que se refere ao seu conteúdo, titularidade e eficácia. A doutrina costuma dividi-lo em quatro gerações. Incluem-se nos direitos de primeira geração os concernentes à liberdade, que surgiram entre os séculos XVII e XVIII, e compreendem direitos civis e políticos inerentes ao ser humano. Logo após a Segunda Guerra Mundial, no século XIX, surgem os direitos sociais, que buscavam uma igualdade material entre os cidadãos, chamados de direitos de segunda geração. A partir do século $\mathrm{XX}$, com o amadurecimento de valores da sociedade nascem os direitos de terceira geração, aqui compreendidos os direitos coletivos e difusos, incluindo entre estes o meio ambiente, direito fundamental objeto deste estudo. E a quarta geração de direitos compreende os direitos das minorias. 
A concepção do direito ambiental como um direito fundamental previsto na Constituição Federal gerou a necessidade de uma tutela efetiva para o meio ambiente, uma vez que o desenvolvimento da sociedade provocou um desequilíbrio ecológico. Assim, foram criadas normas protetivas ao meio ambiente em todo o globo terrestre, sendo que o Brasil possui uma das legislações mais completas na área ambiental. Contudo, a fim de se atingir resultados concretos na tutela do meio ambiente um moderno sistema processual se faz necessário, porém até o momento não existe um sistema codificado para disciplinar processo de demandas coletivas. Assim, adotou-se a utilização de um microssistema processual ambiental, formado pela integração da Lei da Ação Civil Pública (Lei no 7.347/1985) e do Código de Defesa do Consumidor (Lei no 8.078/1990), aplicando-se subsidiariamente a estes o Código de Processo Civil.

Atualmente, a ação civil pública é o instrumento processual mais utilizado para tutelar os interesses metaindividuais protegidos pela norma constitucional, aqui destacado o meio ambiente ecologicamente equilibrado.

Porém, as demandas judiciais sofrem a morosidade da justiça, e devido as suas características, um dano ambiental pode tornar-se irreversível quando não reparado em tempo hábil, causando prejuízos à coletividade. Assim, a possibilidade de obtenção de medidas de urgência nas lides ambientais torna-se fundamental à preservação do meio ambiente. Objetivando solucionar a morosidade da justiça brasileira o Novo Código de Processo Civil (Lei 13.105/2015) alterou regras para a concessão de tutelas provisórias.

Em razão do exposto, tratando-se da ação civil pública ser o principal meio judicial utilizado para tutelar o meio ambiente, devido à importância da concessão das tutelas de urgência nas questões de Direito Ambiental, e em decorrência das modificações sofridas neste tema no Novo Código de Processo Civil, busca com este trabalho analisar eventuais alterações ocorridas na concessão de tutelas de urgência nas nesta classe processual com o advento do Novo Código de Processo Civil (NCPC).

\section{METODOLOGIA}

O presente trabalho empregou pesquisas à legislação nacional e doutrinas relevantes na matéria objeto de estudo. Utilizando o método dedutivo para sistematizar os dados coletados, a fim de cumprir o objetivo proposto.

\section{MICROSSISTEMA PROCESSUAL COLETIVO}

Em sede de jurisdição civil no Brasil existem dois sistemas de tutela processual: o Código de Processo Civil, aplicável às lides individuais, e o microssistema processual coletivo, destinado à tutela de interesses transindividuais. Sendo que, um microssistema legal é constituído pela aplicação conjunta de normas que versam sobre uma matéria específica, cuja abrangência e particularidades exijam mais de uma norma para efetivação de seus propósitos.

Assim, em razão das particularidades dos direitos difusos descritas no artigo 81 , $\S$ único, inciso I, da Lei 8.078/1990, ou seja, sua natureza indivisível e titularidade indeterminada a tutela jurisdicional desses direitos metaindiviuais requer regras processuais próprias. E para tanto, é utilizado no Brasil o microssistema processual coletivo.

O microssistema processual coletivo é constituído essencialmente pela interação de dois diplomas legais fundamentais, a Lei da Ação Civil Pública (Lei n. 7.347/85) e o Código de Defesa do Consumidor (Lei n. 8.078/90), aplicando-Ihes subsidiariamente o Código de Processo Civil. Porém, em situações específicas faz-se o uso de algumas leis especiais, como: a Lei de Ação Popular (Lei n. 4.717/65), a Lei da Ação Direta de Inconstitucionalidade (Lei n. 9.868/99) e a Lei do Mandado de Segurança (Lei n. 12.016/2009). Portanto, para a tutela do meio ambiente ecologicamente equilibrado utilizam-se as técnicas processais existentes no microssistema processual coletivo, uma vez que o direito ambiental, como mencionado anteriormente, é considerado um direito difuso, ou seja, pertencente à coletividade.

\section{AÇÃO CIVIL PUBLICA AMBIENTAL}

A Ação Civil Pública (ACP) destina-se à defesa dos direitos difusos, coletivos e individuais homogêneos. Portanto, é utilizada para tutelar a proteção de bens de natureza metaindividual, sendo um dos principais meios judiciais de proteção ambiental. Segundo Antunes (2010), dentre os bens jurídicos tutelados pela Lei da Ação Civil Pública o meio ambiente é o que merece maior destaque, sendo o que melhor permite a ampliação do instrumento processual em análise. O artigo I 9 da Lei no 7.347, de 24 de julho de 1985, Lei da Ação Civil Pública, determina que:

Art. 10 Regem-se pelas disposições desta lei, sem prejuízo da ação popular, as ações de responsabilidade por 
danos causados: I - ao meio ambiente; II - ao consumidor; III - a bens e direitos de valor artístico, estético, histórico, turístico e paisagístico; IV - a qualquer outro interesse difuso ou coletivo.

Como medida preparatória para eventual ajuizamento de uma Ação Civil Pública Ambiental pode-se instaurar um Inquérito Civil Ambiental. Este procedimento inquisitório destina-se a averiguar a existência de circunstâncias que enseje a aplicação da Lei de Política Nacional do Meio Ambiente (Lei 6.938/81), porém sua instauração não é obrigatória, uma vez que havendo elementos suficientes a Ação Civil Pública Ambiental pode ser prontamente ajuizada (FIORILLO; RODRIGUES; NERY, 1996).

São legitimadas para propor uma Ação Civil Pública às pessoas jurídicas elencadas no artigo 5ㅇ, da Lei 7.347/85: o Ministério Público; a Defensoria Pública; a União, os Estados, o Distrito Federal e os Municípios; a autarquia, empresa publicas, fundação ou sociedade de economia mista; e associações, existindo assim, a possibilidade de haver litisconsórcio no pólo ativo das ações civis públicas ambientais. Quanto ao pólo passivo é licito ao autor ou autores da lide litigar contra um ou contra todos os responsáveis pelo dano ambiental.

Apesar de ser destinada a tutelar direitos da coletividade, havendo danos individuais, podese, a partir de uma sentença condenatória proferida em uma Ação Civil Pública Ambiental, ser promovida a liquidação do dano individual consequente.

Sendo assim, a Ação Civil Pública que versa sobre matéria ambiental é um importante meio judicial para proteção e reparação do meio ambiente, garantindo às gerações, atual e futura, um ambiente ecologicamente equilibrado.

\section{TUTELA DE URGÊNCIA NO MICROSSISTEMA PROCESSUAL CIVIL AMBIENTAL}

A tutela do meio ambiente fundamenta-se em dois princípios acauteladores do dano ambiental: o princípio da prevenção e o da precaução. $\mathrm{Na}$ prevenção cuida-se dos danos decorrentes da atividade humana sobre o meio ambiente que tenham suas dimensões conhecidas pelas ciências. Enquanto que na precaução visa-se proteger o meio ambiente de danos dos quais não se tem informações certas sobre suas consequências (PROCHNOW, 2009).
Portanto, o fator tempo na tutela ambiental é fundamental para efetiva proteção do meio ambiente, tendo em vista que o objetivo do direito ambiental é sempre a preservação e não o alcance de uma indenização ao final do processo. Porém, levando-se em consideração a morosidade da justiça, medidas de urgência se impõem a fim de legitimar o processo ambiental como instrumento de direito material, uma vez que estas técnicas processuais provisórias visam minimizar os danos que o lapso temporal causa ao direito discutido na lide.

Segundo Rodrigues (2015), as medidas de urgência se impõem no processo ambiental devido à fragilidade do meio ambiente e por suas características que são: a ubiquidade (o bem ambiental é onipresente); a instabilidade; e a essencialidade (é imprescindível à manutenção, ao abrigo e à proteção das formas de vida). Assim, tratando-se de meio ambiente, necessita-se da utilização de técnicas processuais de urgência na prestação da tutela jurisdicional, visando proteção ou reparação do ambiente ecologicamente equilibrado, exigindo-se apenas tão somente um grau mínimo de probabilidade para a concessão dessas medidas.

As medidas de urgência aplicáveis à tutela coletiva ambiental podem ser: cautelar, antecipatória ou liminar. Nas Ações Civis Públicas que versam sobre matéria ambiental a cautelaridade é regulada pelo artigo 4ㅇ da Lei no $7.347 / 85$, utilizada, por exemplo, para paralisar atividades nocivas enquanto procedimentos investigatórios ainda não encontram-se exauridos. A antecipação da tutela é disciplinada, segundo Dantas (2010), pelos artigos 12 da Lei 7.347/85 e artigo 84, § $3 \circ$ da Lei 8.078/90, quando concedidas initio litis, por tratar-se de liminar, e quando se trata de antecipação de tutela no curso do processo, seu fundamento legal será no Código de Processo Civil, isto em razão de que havendo disciplina própria no sistema processual coletivo esta deve ser privilegiada.

Assim, continua o autor informando que, para a concessão de tutelas a posteriori deve-se recorrer às regras dos $\S \S 30,60$ e 70 do art. 273 do Código de Processo Civil de 1973. Quanto à tutela liminar, que visa evitar ou cessar danos através de um mandado liminar, segue-se pelo disposto no artigo 12 da Lei de Ação Civil Pública. A chamada tutela inibitória, muito utilizada nas demandas ambientais, pode-se dar pela imposição de uma obrigação de fazer ou não fazer cumulada de multa, conforme artigo 84 do CDC e 11 da LACP. 
Com o advento do Novo Código de Processo Civil (Lei no 13.105/2015) as regras de concessão de tutelas de urgência aplicáveis aos processos cíveis sofreram alterações. No novo código as medidas cautelares e antecipatórias encontram-se no mesmo livro e apresentam os mesmos requisitos, sendo eles: a probabilidade do direito e o perigo de dano ou risco ao resultado útil do processo. Em razão de o dano ambiental ser de difícil reparação ou mesmo irreparável essa mudança não acarretará grandes alterações para a tutela do meio ambiente (LACERDA, 2016).

Conforme ensina Cunha (2012), neste novo diploma cabe ao magistrado analisar a natureza da tutela de urgência requerida, adequando o pedido ao procedimento cabível, sendo que as cautelares seguem o disposto nos artigos 305 a 310 do Novo Código de Processo Civil (NCPC)e as de caráter antecipatório o que disciplina os artigos 303 e 304 do mesmo diploma processual civil recentemente alterado.

Uma inovação trazida pelo NCPC é a chamada tutela de evidência (artigo 311, inciso IV, do Novo Código de Processo Civil), que prescreve que tendo o autor prova documental suficiente dos fatos constitutivos, aos quais o réu não apresente prova capaz de gerar dúvida razoável, a tutela de evidência será concedida. Assim, ajuizada uma ação civil pública ambiental o réu deverá apresentar provas, não somente alegar negativa de responsabilidade, sob pena de concessão da antecipação da própria tutela (SALES, 2015).

\section{CONCLUSÃO}

Com o presente trabalho buscou-se analisar a importância da concessão de tutelas de urgência nas ações civis públicas ambientais, bem como, verificar se com o advento do Novo Código de Processo Civil ocorreram modificações na concessão destas.

Sabe-se, portanto, que as ações civis públicas ambientais constituem o principal meio judicial utilizado para tutelar o equilíbrio ecológico, utilizando-se em seu processamento as técnicas processuais disciplinadas pelo microssistema processual ambiental. Pois bem, objetivando a proteção preventiva do meio ambiente, em razão de sua fragilidade, as medidas de urgência se impõem a fim de minimizar os danos que o lapso temporal causa ao direito que se discute nesses processos.

O presente estudo constatou ainda, que o Novo Código de Processo Civil trouxe alterações aplicáveis nas concessões de tutelas provisórias nas lides ambientais, garantindo até a antecipação da própria tutela de interesse da lide, desde que o pedido esteja bem fundamentado e documentado, almejando a proteção ambiental.

\section{REFERÊNCIAS}

ANTUNES, P. de B. Direito ambiental. 12. ed. Rio de Janeiro : Lumen Juris, 2010.

CUNHA, A. S. Introdução ao estudo do direito. 1. ed. São Paulo : Saraiva, 2012.

DANTAS, M. B. Ação civil pública e meio ambiente: teoria geral do processo, tutela jurisdicional e execução/cumprimento. 1. ed. São Paulo : Saraiva, 2010.

FIORILLO, C. A. ; RODRIGUES, M. A. ; NERY, R. M. A. Direito processual ambiental brasileiro. 1 . ed. Belo Horizonte: Del Rey, 1996.

LACERDA, S. M. Um estudo sobre o uso da tutela de urgência para a melhoria da prevenção e da precaução na defesa do meio ambiente. 2016. 104 f. Monografia de Conclusão de Curso (Graduação em Direito) - Universidade de Brasília, Brasília.

PROCHNOW, K. E. A tutela de urgência nas lides ambientais como instrumento de concretização dos princípios da prevenção e da precaução. Âmbito Jurídico, Rio Grande, v.12, n. 65, jun. 2009. RODRIGUES, M. A. Direito ambiental esquematizado. 2. ed. São Paulo: Saraiva, 2015.

SALES, R. B. A aplicação do princípio da cooperação: ação civil pública e tutela ambiental efetiva. 2015. 100 f. Dissertação (Mestrado em Direito) - Universidade Católica de Santos, Santos.

Recebido para publicação em 17/08/2016

Revisado em 25/08/2016

Aceito em 26/08/2016 